\title{
Differential proteomic profiling of primary and recurrent chordomas
}

\author{
SU CHEN $^{1 *}$, WEI XU $^{1 *}$, JIAN JIAO $^{1}$, DONGJIE JIANG $^{1}$, JIAN LIU $^{2}$, TENGHUI CHEN $^{3}$, \\ ZONGMIAO WAN $^{1}$, LEQIN XU ${ }^{1}$, ZHENHUA ZHOU $^{1}$ and JIANRU XIAO ${ }^{1}$ \\ ${ }^{1}$ Department of Bone Tumor Surgery, Changzheng Hospital, Second Military Medical University, \\ Shanghai 200003, P.R. China; ${ }^{2}$ Department of Molecular and Cellular Biology, \\ Baylor College of Medicine; ${ }^{3}$ Department of Bioinformatics and Computational Biology, \\ The University of Texas M.D. Anderson Cancer Center, Houston, TX 77030, USA
}

Received October 12, 2014; Accepted December 19, 2014

DOI: $10.3892 /$ or.2015.3818

\begin{abstract}
Chordomas are locally destructive tumors with high rates of recurrence and a poor prognosis. The mechanisms involved in chordoma recurrence remain largely unknown. In the present study, we examined the proteomic profile of a chordoma primary tumor (CSO) and a recurrent tumor (CSR) through mass spectrum in a chordoma patient who underwent surgery. Bioinformatic analysis of the profile showed that 359 proteins had a significant expression difference and 21 pathways had a striking alteration between the $\mathrm{CSO}$ and the CSR. The CSR showed a significant increase in carbohydrate metabolism. Immunohistochemistry (IHC) confirmed that the cancer stem cell marker activated leukocyte cell adhesion molecule (ALCAM or CD166) expression level was higher in the recurrent than that in the primary tumor. The present study analyzed the proteomic profile change between CSO and CSR and identified a new biomarker ALCAM in recurrent chordomas. This finding sheds light on unraveling the pathophysiology of chordoma recurrence and on exploring more effective prognostic biomarkers and targeted therapies against this devastating disease.
\end{abstract}

\section{Introduction}

Chordoma is a rare slow-growing neoplasm thought to arise from cellular remnants of the notochord. The incidence of chordoma is approximately 1 case in one million individuals and it accounts for $\sim 1-4 \%$ of all tumor cases. However, these rare tumors present very significant treatment challenges (1). It

Correspondence to: Professor Jianru Xiao, Department of Bone Tumor Surgery, Changzheng Hospital, Second Military Medical University, 415 Fengyang Road, Shanghai 200003, P.R. China E-mail: jrx_cz@163.com

${ }^{*}$ Contributed equally

Key words: proteome, chordomas, bioinformation, ALCAM is notable that $67 \%$ of the surgically managed patients suffer local recurrence, and the disease-free survival at 5 years is almost $0 \%(1,2)$.

Complete surgical resection followed by radiation therapy offers the best chance of long-term control for chordoma. However, incomplete resection of the primary tumor makes controlling the disease more difficult and increases the odds of recurrence. Tumors at certain sites such as skull base chordoma can hardly be removed completely due to the complicated peritumoral tissue structure which makes the tumor difficult to be exposed. Thus, recurrence of skull base chordoma is as high as $85 \%$. Chordomas are relatively radioresistant as well, requiring high doses of radiation to be controlled. The proximity of chordomas to vital neurological structures such as the brain stem and nerves limits the dose of radiation that can safely be delivered. A strategy to control the recurrence of chordomas is vital for improving the survival rate of patients. It is imperative to explore chordoma recurrence mechanisms at the molecular level and to search for alternative therapeutic methods including chemotherapy to treat it. Recently, Zhou et al assessed the chordoma proteome in chordoma tumor tissues and identified ENO1, PKM2, and gp96 proteins as being upregulated in chordomas. They reported that the expression of these proteins was higher in recurrent than that in the primary chordomas (3). However, the molecular mechanisms involved in chordoma recurrence remain unstudied, and the detailed changes in proteomic profiling in the process of recurrence remain unclear.

We analyzed 3,296 proteins identified by mass spectrum in a chordoma patient original tumor (CSO) and recurrent tumor (CSR) tissue. Bioconductor's Global Anova test was applied to compare the overall proteomic profiling changes between CSO and CSR which indicated there was a significant difference $(\mathrm{P} \leq 0.1)$. Bioconductor's multtest found that 359 proteins exhibited the highest expression difference between CSO and CSR. KEGG database analysis of the 359 proteins revealed that 21 pathways had a significant change between CSO and CSR. Immunohistochemistry (IHC) further verified that cancer stem cell marker activated leukocyte cell adhesion molecule (ALCAM or CD166) was markedly upregulated in the CSR tissue. 


\section{Materials and methods}

Tissue specimen processing. Chordoma specimens were obtained from a resected tumor following an institutional review board approved protocol. The histological composition of the samples was assessed by examining adjacent sections. Tumor samples were dissected and only tissue that was superfluous to that required for pathological evaluation was taken. The samples were immediately snap-frozen in liquid nitrogen and stored at $-80^{\circ} \mathrm{C}$. Approximately $800 \mu \mathrm{g}$ of tissue samples was cut into small pieces with a scalpel and transferred into a mortar filled with liquid nitrogen. The tissue was ground to a fine powder with a pestle in the continuous presence of liquid nitrogen and transferred into a reaction tube with extraction buffer [ $2 \mathrm{M}$ thiocarbamide, $7 \mathrm{M}$ urea and $10 \mu \mathrm{M}$ proteinase inhibitor (Roche Diagnostics, Indianapolis, IN, USA)] at $4^{\circ} \mathrm{C}$. The solution was centrifuged at $16,000 \mathrm{xg}$ at $4^{\circ} \mathrm{C}$ for $15 \mathrm{~min}$, and the supernatant $(\sim 300-400 \mu \mathrm{l})$ was stored frozen at $-200^{\circ} \mathrm{C}$.

Proteome analysis. The protein concentration was determined by Amersham 2D Quant kit (GE Healthcare Bio-Sciences, Piscataway, NJ, USA). The protein samples were further lysed to peptides and prepared for proteome analysis as described previously (4). Peptides were analyzed using strong cation (SCX)/reversed phase, upgrade performance liquid chromatography (Nano-RPLC)/ESI/MS/MS. Samples were analyzed using a LTQ Orbitrap XL (Thermo Electron Corp., Bremen, Germany) mass spectrometer. MS/MS spectra data were searched against the Swiss-Prot Human (2009.02.10, 20331 sequences) database or IPI database using Bioworks Browser 3.3.1 SP1. The identified proteins were quantified by APEX software $(5,6)$. To control the false-positive rate, finally the quantitative results by false-discovery rate (FDR) $1 \%$ or less (false-positive rate of $1 \%$ or less) as the standard filter.

Immunohistochemistry. The paraffin sections were dried in an oven at $65^{\circ} \mathrm{C}$ for $1 \mathrm{~h}$. The paraffin sections were then dewaxed in xylene and rehydrated in a series of ethanol solutions. The endogenous peroxidase activity was blocked by a $10-\mathrm{min}$ pre-incubation with $3 \% \mathrm{H}_{2} \mathrm{O}_{2}$. The paraffin sections were preheated at $100^{\circ} \mathrm{C}$ in antigen retrieval solution containing EDTA (pH 8.0) for 30 min and blocked by non-immune goat serum at room temperature for $15 \mathrm{~min}$ to decrease unspecific staining. Incubation with mouse polyclonal anti-ALCAM (1:1,000 dilution) was performed overnight at $4^{\circ} \mathrm{C}$. After being washed 3 times with $1 \mathrm{X}$ PBS buffer for $3 \mathrm{~min}$, the sections were incubated with the secondary (link) antibody (biotinylated mouse-anti-human $\operatorname{IgG}$ ) for $30 \mathrm{~min}$ at room temperature. After reacting with the streptavidin-biotin-peroxidase complex for $20 \mathrm{~min}$, the immunoreactivity was determined by 3,3'-diamino-benzidine tetrahydrochloride and $\mathrm{H}_{2} \mathrm{O}_{2}$ at room temperature according to the manufacturer's instructions. The positive reaction was manifested as brown (DAB) staining. The sections were counterstained in Mayer's hematoxylin. The selected sections were scanned at $\mathrm{x} 400$ magnification to visualize the localization and distribution of ALCAM.

Statistical analysis. Statistically significant proteins were identified by first performing a two-tailed Student's t-test with the 'multtest' package in rat the respective time-points by comparing protein abundance between CSO and CSR. Multiple hypothesis testing was then implemented with the 'rawp2adjp' function in R by correcting the P-values according to Benjamini and Hochberg procedures (7) to control the FDRs to $\leq 1 \%$. Proteins with a FDR $\leq 1 \%$, peptide count $\geq 3$, and fold-change $\geq 2$ were identified as statistically significant. Throughout the present study, upregulation is defined as higher protein abundance measured in CSR relative to CSO and downregulation refers to fewer proteins measured with CSR. Moreover, a positive expression ratio represents upregulation and negative represents downregulation. Blast2Go (8) was used as a comprehensive bioinformatics tool for the functional annotation of the protein sequences in the present study such as determining gene ontology terms. The metabolic map at CSR was generated by first using the statistically significant proteins to identify the key pathways. Once the pathways were identified, all of the detected proteins in the same pathway were evaluated to determine whether they were upregulated or downregulated relative to the control. If $\geq 50 \%$ of the proteins in the pathway was regulated similarly in the same direction, then the pathway would be designated as upregulated or downregulated according to the majority. The cellular pathways are displayed using the iPath 2.0 platform (9).

\section{Results and Discussion}

In order to obtain a comprehensive proteomic profile of CSO and CSR and to investigate the mechanism of recurrence, the proteome of patient CSO and CSR tumor tissue samples was analyzed with LC/MS. In total, 3,296 unique protein sequences were identified. Bioconductor's Global Anova package was used to determine the significance of the protein expression change between CSO and CSR. A protein expression difference with $\mathrm{P} \leq 0.1 \pm 0.002$ was defined as statistically significant (Table I). Furthermore, we applied Bioconductor's multtest package to analyze the identified 3,296 proteins and found that a large number of proteins (359) showed significant changes in expression with $\mathrm{BH} \leq 0.01$ and $\mathrm{P} \leq 0.01$ between CSO and CSR. These proteins were involved in central metabolism, genetic information transcription and other processes essential to cell functions. Of these 359 proteins, there were 244 downregulated proteins $(\mathrm{CSR} / \mathrm{CSO}$ value $\leq 0.1)$ and 115 upregulated proteins (CSR/CSO $\geq 9$ ) (Fig. 1; Table III and IV). This analysis discovered many significant proteins which have never been reported before in recurrent chordomas.

Among the top downregulated proteins, podocan is involved in negative regulation of cell migration and proliferation, concomitant with increased p21 expression which is a tumor-suppressor gene and can mediate cellular senescence (10). ZO-1 has been shown to be downregulated in poorly differentiated, highly invasive breast cancer cell lines (11), and downregulation of complement factor I (CFI) is regarded as a potential suppressive protein for gastric cancer identified by serum proteome analysis (12). Downregulation of osteomodulin (OMD) is referred to in the context of uterine serous papillary carcinoma. It was further disclosed that activation of OMD or/and PRELP gene expression or function can suppress cancer initiation and development (13). FK506-binding protein 4 (FKBP4) was reported to have cancer-specific methylation which usually inactivates this 
Table I. Global test for differential gene expression.

\begin{tabular}{lcrr}
\hline ANOVA & SSQ & \multicolumn{1}{c}{ DF } & \multicolumn{1}{c}{ MS } \\
\hline Effect & 0.002073207 & 3296 & $6.29007 \mathrm{E}-07$ \\
Error & 0.00065985 & 13184 & $5.00493 \mathrm{E}-08$ \\
Test Result & & & \\
F.value & 12.56774798 & & \\
p.perm & 0.1 & & \\
p.approx & 0.002139239 & & \\
\hline
\end{tabular}

" $\mathrm{p} \leq 0.1$.

Table II. KEGG database identified 21 pathways with Seqs $\geq 3$.

\begin{tabular}{lrr}
\hline Pathways & \#Seqs & \#Enzs \\
\hline Purine metabolism & 10 & 11 \\
Arginine and proline metabolism & 5 & 6 \\
Starch and sucrose metabolism & 5 & 6 \\
Pyruvate metabolism & 4 & 4 \\
Glycolysis/gluconeogenesis & 4 & 4 \\
Oxidative phosphorylation & 4 & 2 \\
Alanine, aspartate and glutamate metabolism & 4 & 5 \\
Cysteine and methionine metabolism & 4 & 5 \\
Aminoacyl-tRNA biosynthesis & 3 & 3 \\
Butanoate metabolism & 3 & 3 \\
Methane metabolism & 3 & 3 \\
Streptomycin biosynthesis & 3 & 3 \\
Amino sugar and nucleotide sugar metabolism & 3 & 5 \\
Propanoate metabolism & 3 & 4 \\
Valine, leucine and isoleucine degradation & 3 & 3 \\
3-alanine metabolism & 3 & 4 \\
Drug metabolism - other enzymes & 3 & 2 \\
Glyoxylate and dicarboxylate metabolism & 3 & 3 \\
Phosphatidylinositol signaling system & 3 & 3 \\
Inositol phosphate metabolism & 3 & 3 \\
Pyrimidine metabolism & 3 & 3 \\
\end{tabular}

gene in breast cancer tissues (14). We are the first to report downregulation of these tumor-suppressing proteins in recurrent chordomas. The markedly decreased expression of these tumor-suppressing proteins suggests that recurrent chordomas are more aggressive than primary chordomas. While the top upregulated proteins included myosin-7 (MYH7) which is related to eukaryotic cell motility; CD166 (ALCAM) has been regarded as a potential cancer stem cell marker (15). Splicing factor, arginine/serine-rich 2 (SFRS2) demonstrated Wnt signaling-dependent activation which promotes cell migration (16); and Ras-related protein Rab-11A (RAB11A) can differentially modulate epidermal growth factor-induced proliferation and motility in immortal breast cells (17). These newly identified upregulated molecules in recurrent chordomas by our analysis may be possible biomarkers for diagnosis and/ or targets for treating recurrent chordomas. Our study also provides valuable information for future studies on chordoma recurrence mechanisms which remain unelucidated.
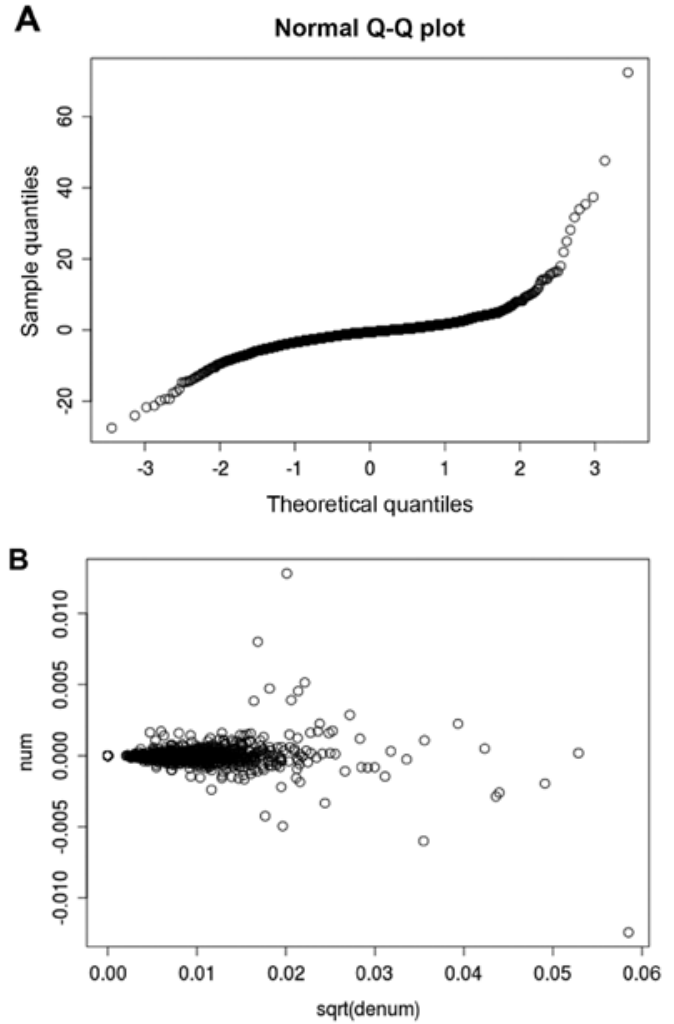

Figure 1. (A) Normal Q-Q plot of t-statistics for the protein data. The points that deviate markedly from an otherwise linear relationship correspond to those genes whose expression levels differ between the CSO and CSR groups. (B) Numerator vs. square root of denominator of the t-statistics for the protein data. The majority of proteins which do not reveal any difference in expression between CSO and CSR groups are represented by points distributed on the $y$-axis around zero. Some of the points that deviate from this area represent the corresponding proteins whose expression levels are higher or lower in the CSR group than that in the CSO group. CSO, chordoma primary tumor; CSR, recurrent tumor.

To investigate which signaling pathways have alterations in CSR, we searched the 359 identified proteins with significant change in the KEGG database and found that there were over 21 pathways with Seqs $\geq 3$ between CSO and CSR as shown in Table II. Eight pathways were markedly upregulated in CSR compared with CSO (num upregulated protein $\geq 60 \%$ ) and nine pathways were apparently downregulated in CSR compared with CSO (num downregulated protein $\geq 60 \%$ ) (Fig. 2). Notably, most of the upregulated pathways (6 of 8) and cellular components are involved in carbohydrate metabolism indicating that carbohydrate metabolic activity was higher in recurrent chordomas than in primary chordomas (Fig. 2). Fig. 3 shows that the top 3 upregulated pathways including butanoate, inositol phosphate and glyoxylate and dicarboxylate metabolism are all involved in carbohydrate metabolism. Those 3 pathways were upregulated by $85.7,75$ and $73.3 \%$, respectively, in the CSR compared with the CSO (Fig. 3). The glycolysis/gluconeogenesis pathway was also upregulated (Fig. 2). It has been reported that a high glycolytic rate has advantages for malignant cells (18). High glycolytic activity produces high levels of lactate and $\mathrm{H}^{+}$ions which are transported outside the cell where they directly promote tumor aggressiveness through invasion and metastasis, two other hallmarks of cancer (19). Additionally, the genes and pathways that upregulate 


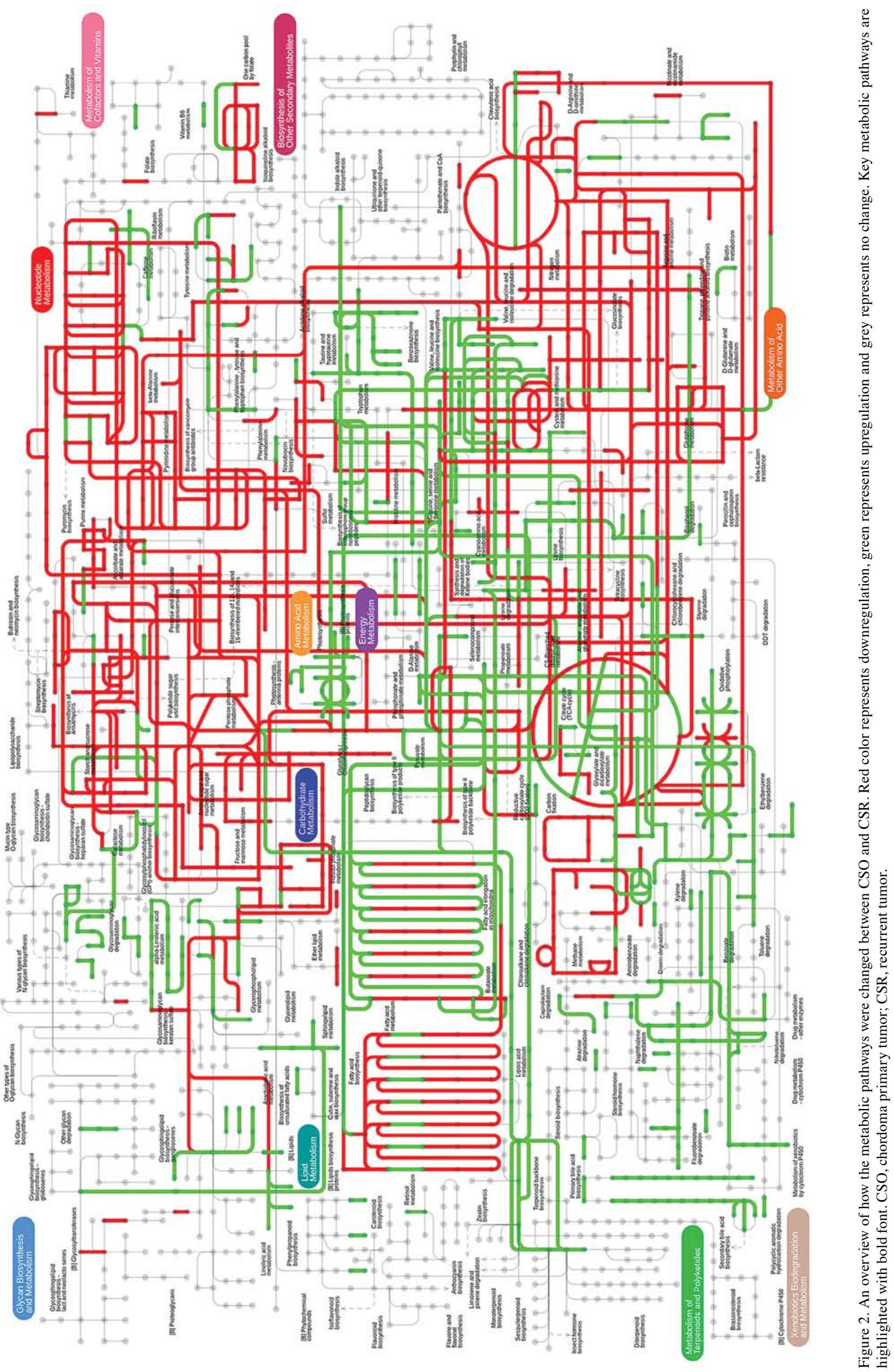


A

BUTANOATE METABOLISM

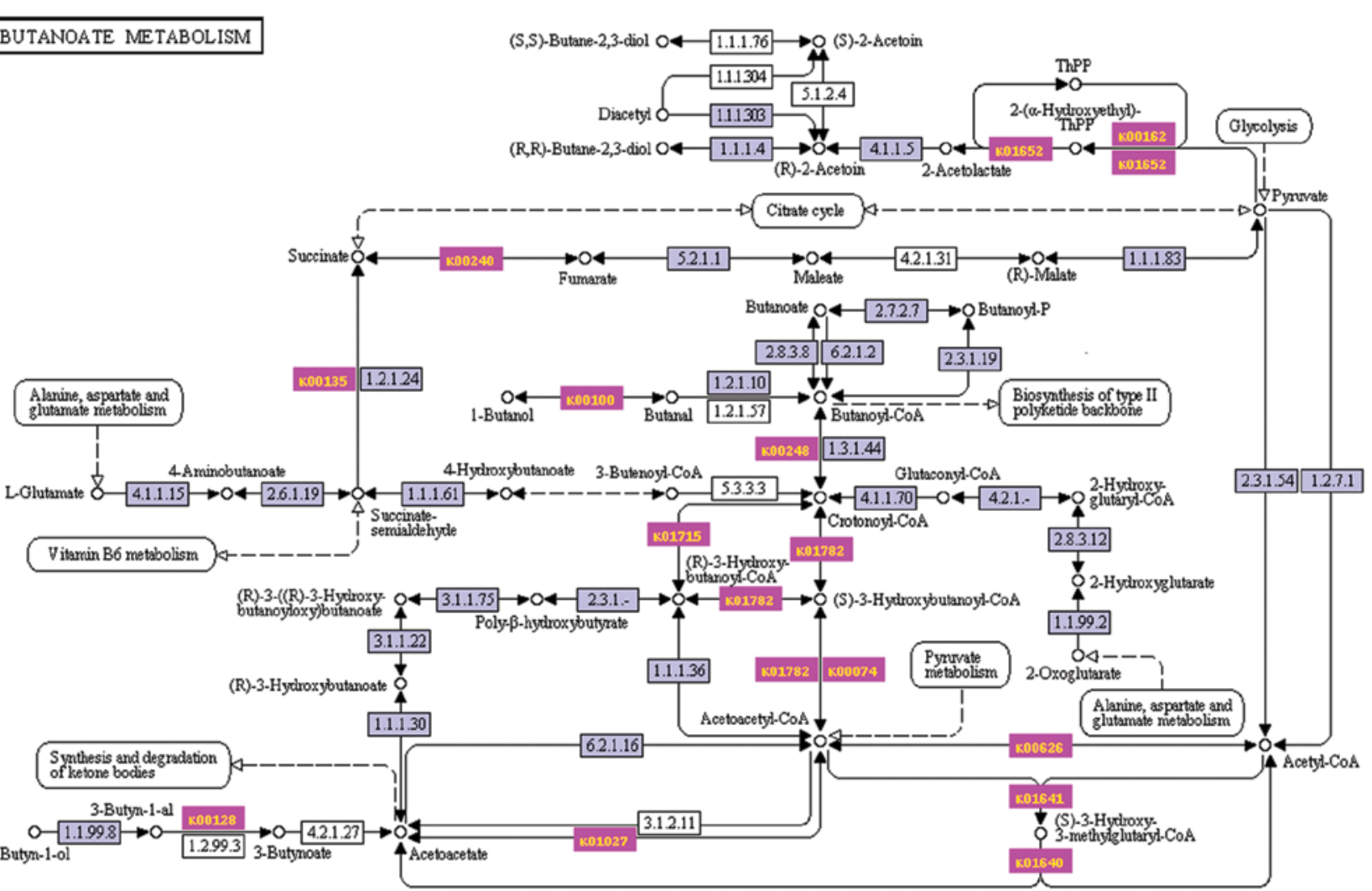

$006505 / 14 / 10$

$006505 / 1410$
(c) Kanthisa Loboratories

B

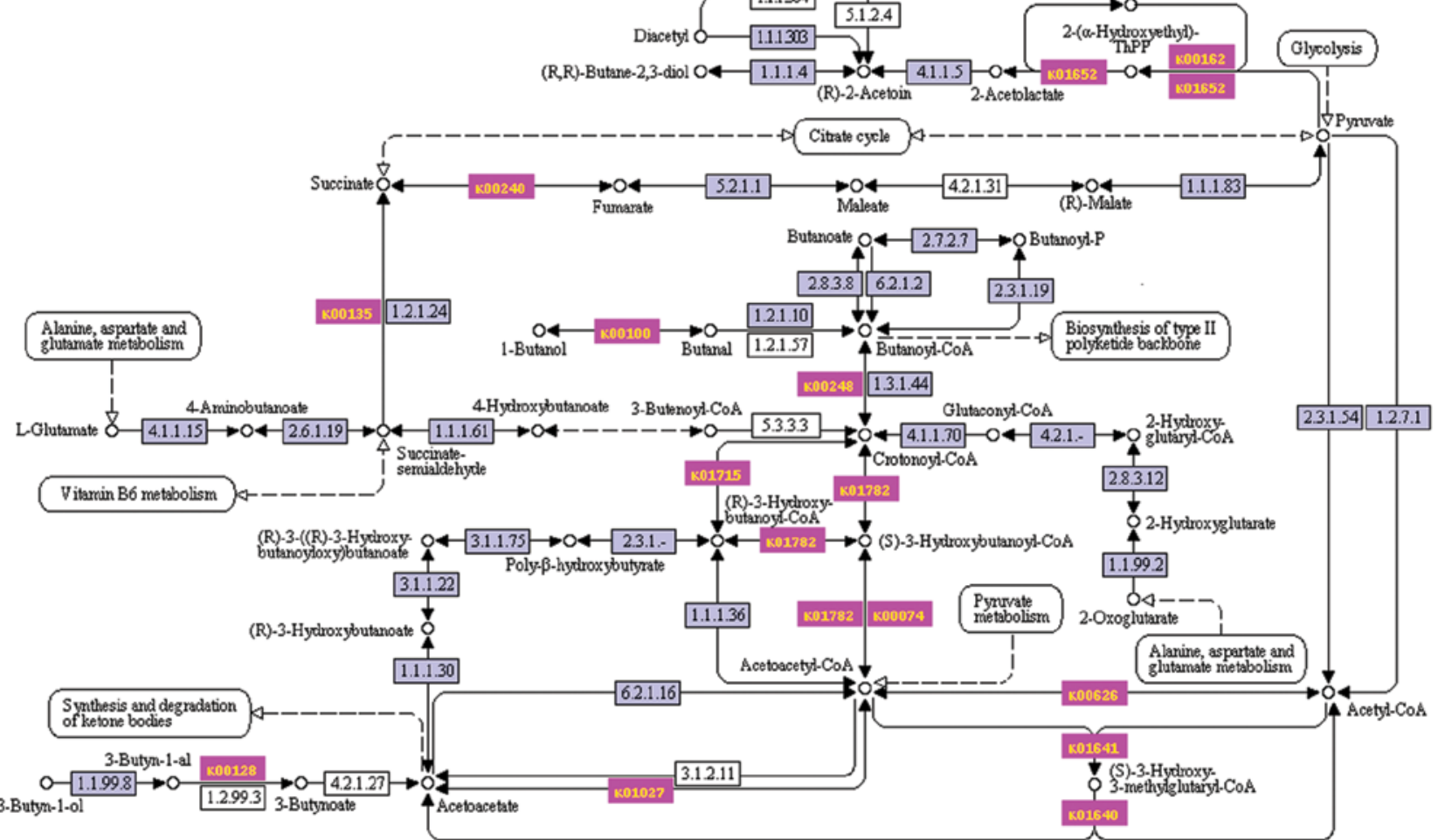

INOSITOL PHOSPHATE METABOLISM

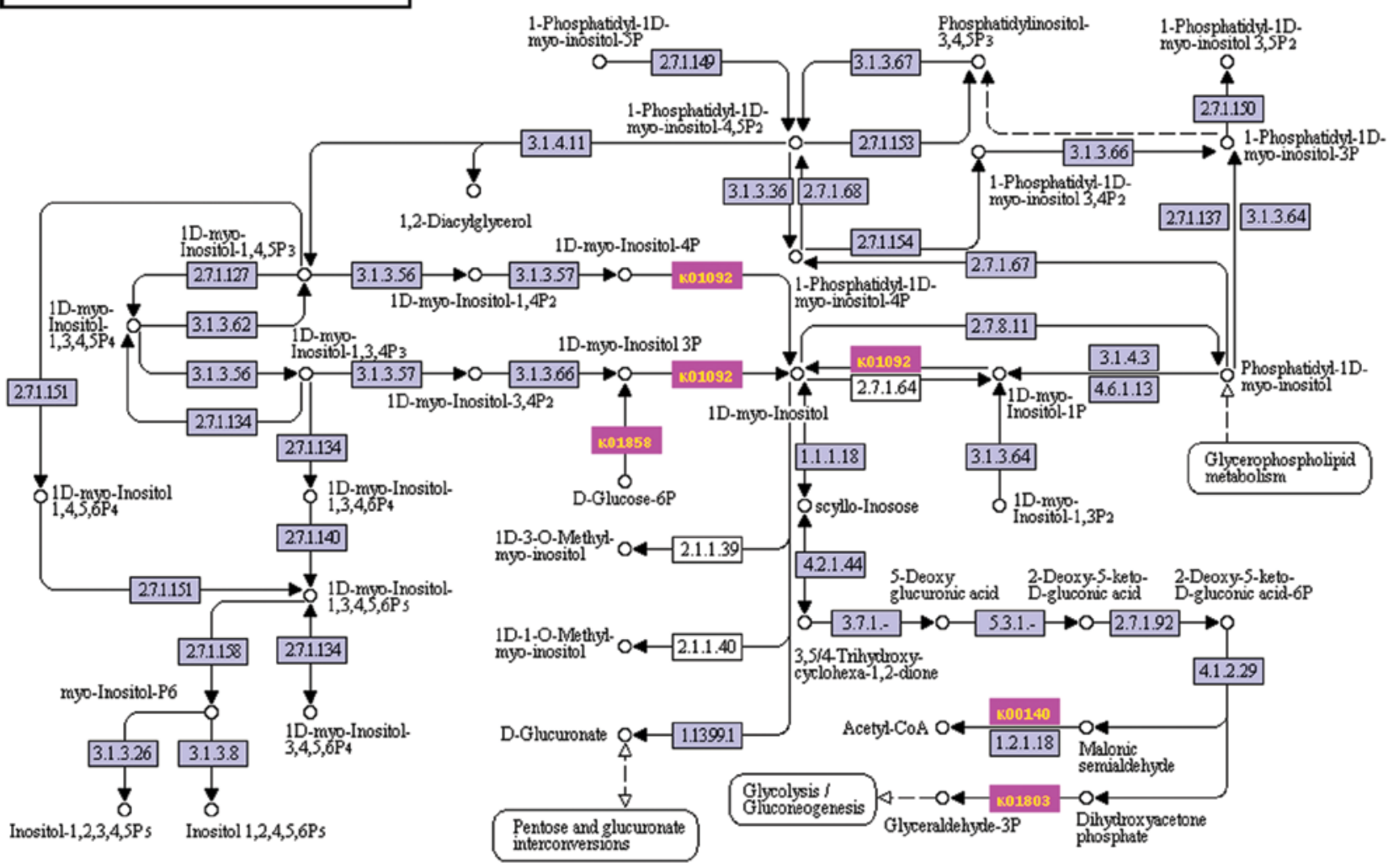

005625110110

(c) Kanehisa Laboratonies

Figure 3. Top upregulated pathways in the KEGG database. (A) Carbohydrate metabolism, butanoatemetabolism pathway. (B) Carbohydrate metabolism, inositol phosphate metabolism. 
C

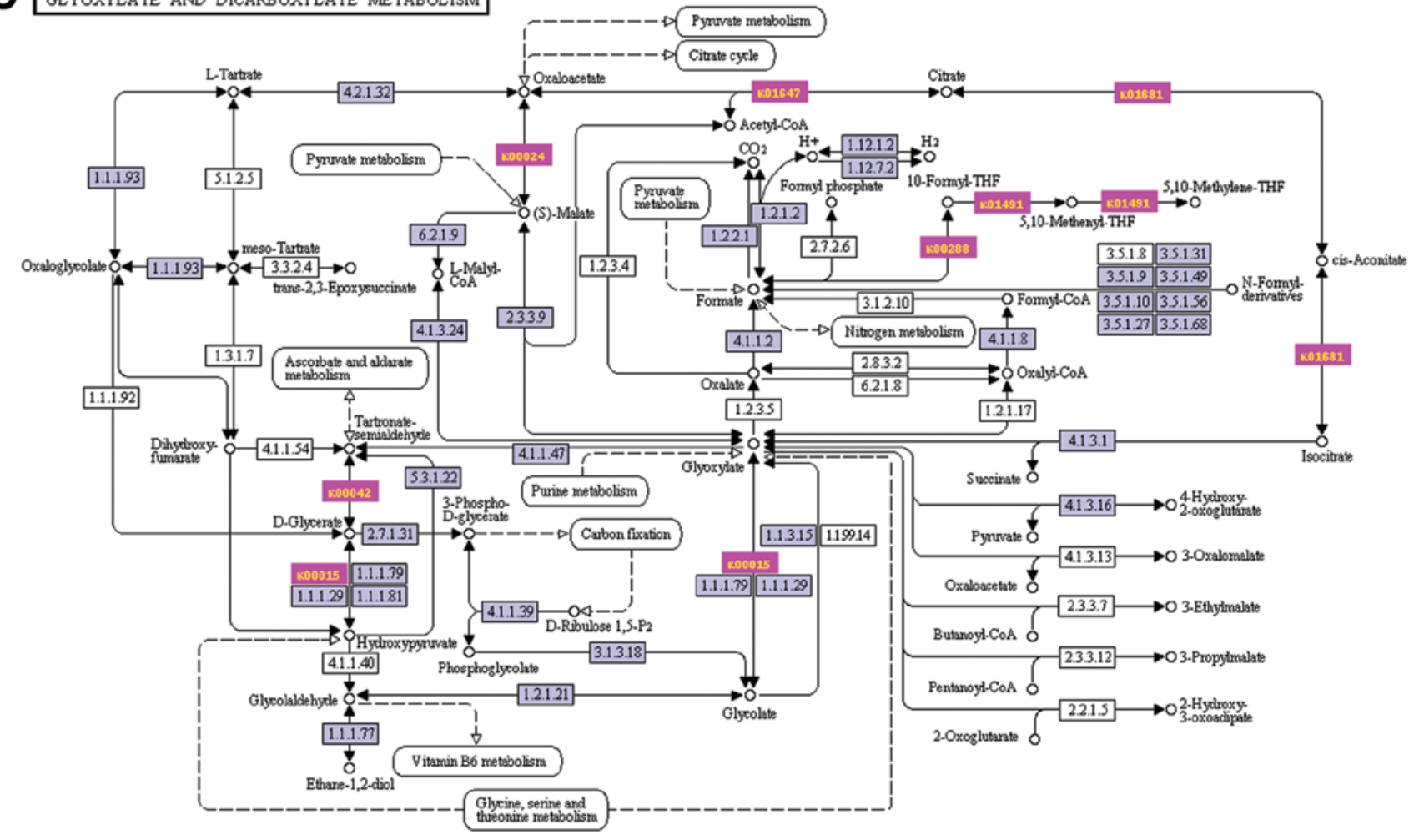

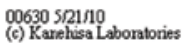

Figure 3. Continued. Top upregulated pathways in the KEGG database. (C) Carbohydrate metabolism, glyoxylate and dicarboxylate metabolism.
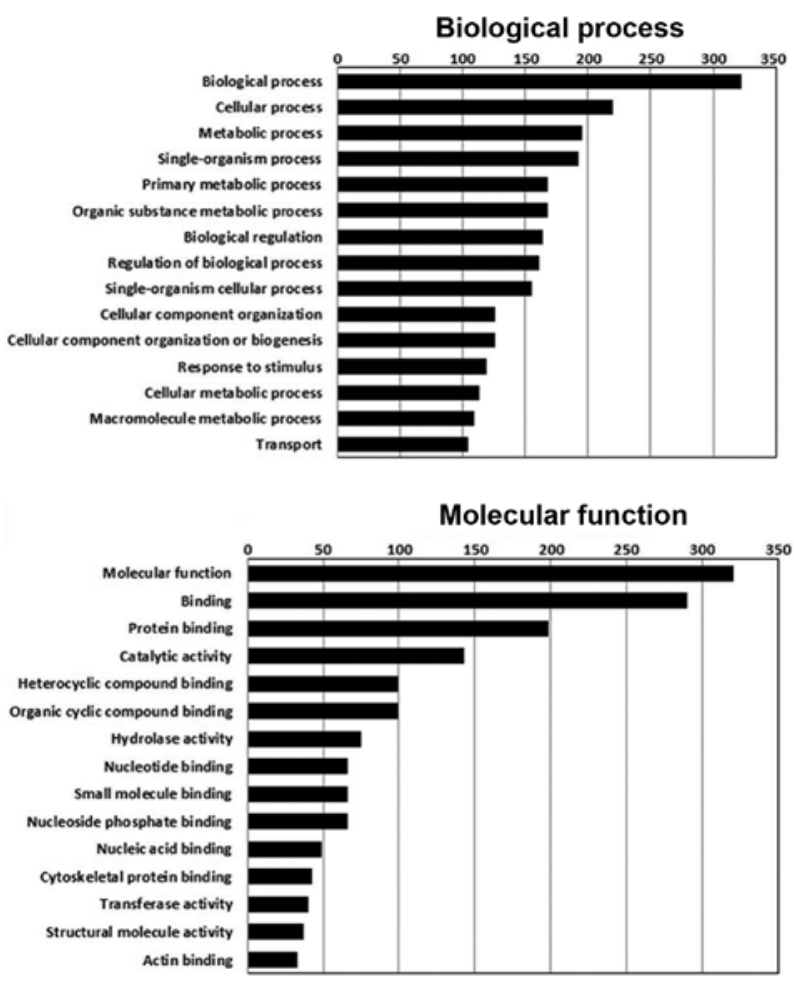

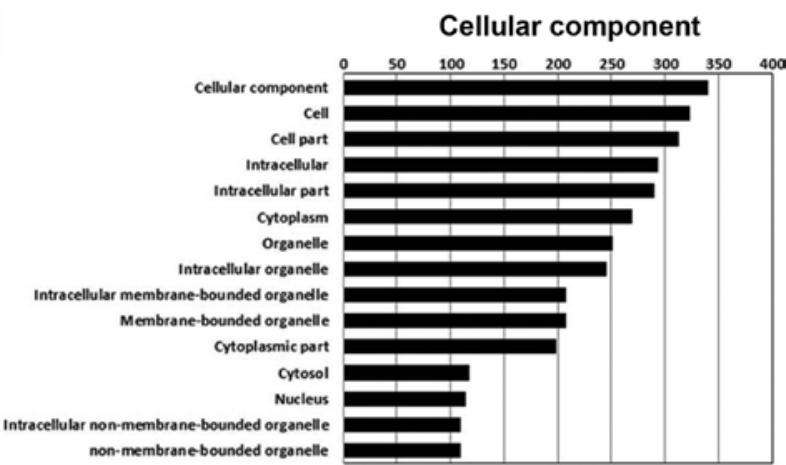

Figure 4. Gene ontology terms of the 359 statistically significant proteins identified in CSO and CSR. The $\mathrm{x}$-axis indicates the number of proteins in each category. CSO, chordoma primary tumor; CSR, recurrent tumor. glycolysis are themselves anti-apoptotic (20). The increased carbohydrate metabolism in recurrent chordomas suggests that recurrent chordomas have a more aggressive phenotype and are resistant to therapy. The other 2 upregulated pathways in the recurrent chordomas are involved in energy metabolism and amino acid metabolism. In contrast to the upregulated pathways, the downregulated pathways participate in various biological processes and molecular functions including 
Table III. Downregulated proteins (244) $(\mathrm{CSR} / \mathrm{CSO}$ value $\leq 0.1)$.

Protein Protein_description

\section{Q7Z5L7 Podocan GN=PODN}

Q7L5N1 COP9 signalosome complex subunit 6 GN=COPS6

P31939 Bifunctional purine biosynthesis protein PURH $\mathrm{GN}=\mathrm{ATIC}$

O94808 Glucosamine-fructose-6-phosphate aminotransferase (isomerizing) $2 \mathrm{GN}=\mathrm{GFPT} 2$

Q8TD55 Pleckstrin homology domain-containing family $\mathrm{O}$ member 2 GN=PLEKHO2

O75400 Pre-mRNA-processing factor 40 homolog A $\mathrm{GN}=\mathrm{PRPF} 40 \mathrm{~A}$

Q6KB66 Keratin, type II cytoskeletal $80 \mathrm{GN=KRT80}$

Q07157 Tight junction protein ZO-1 GN=TJP1

P10155 $60 \mathrm{kDa}$ SS-A/Ro ribonucleoprotein GN=TROVE2

P05156 Complement factor I GN=CFI

Q99983 Osteomodulin GN=OMD

Q02790 FK506-binding protein $4 \mathrm{GN}=\mathrm{FKBP} 4$

Q9Y240 C-type lectin domain family 11 member A GN=CLEC $11 \mathrm{~A}$

Q9H8Y8 Golgi reassembly-stacking protein 2 $\mathrm{GN}=\mathrm{GORASP} 2$

P27658 Collagen $\alpha-1$ (VIII) chain GN=COL8A1

P27169 Serum paraoxonase/arylesterase $1 \mathrm{GN}=\mathrm{PON} 1$

Q99729 Heterogeneous nuclear ribonucleoprotein A/B GN=HNRNPAB

Q9H4A4 Aminopeptidase B GN=RNPEP

P50570 Dynamin-2 GN=DNM2

Q14157 Ubiquitin-associated protein 2-like GN=UBAP2L

P02788 Lactotransferrin GN=LTF

Q96S97 Myeloid-associated differentiation marker GN=MYADM

O60841 Eukaryotic translation initiation factor 5B $\mathrm{GN}=\mathrm{EIF} 5 \mathrm{~B}$

Q96C19 EF-hand domain-containing protein D2 $\mathrm{GN}=\mathrm{EFHD} 2$

P50225 Sulfotransferase 1A1 GN=SULT1A1

A0AVT1 Ubiquitin-like modifier-activating enzyme 6 GN=UBA6

A0MZ66 Shootin-1 GN=KIAA1598

A1L4H1 Scavenger receptor cysteine-rich domain-containing protein LOC284297

A8MWD9 Small nuclear ribonucleoprotein G-like protein

O00154 Cytosolic acyl coenzyme A thioester hydrolase $\mathrm{GN}=\mathrm{ACOT} 7$

O00461 Golgi integral membrane protein 4 GN=GOLIM4

O14791 Apolipoprotein L1 GN=APOL1

O43592 Exportin-T GN=XPOT

O43670 Zinc finger protein $207 \mathrm{GN}=\mathrm{ZNF} 207$

O43847 Nardilysin GN=NRD1

O60240 Perilipin GN=PLIN

O60684 Importin subunit $\alpha-7$ GN=KPNA6

O60687 Sushi repeat-containing protein SRPX2 $\mathrm{GN}=\mathrm{SRPX} 2$

O60831 PRA1 family protein $2 \mathrm{GN}=\mathrm{PRAF} 2$

O75094 Slit homolog 3 protein GN=SLIT3

O75110 Probable phospholipid-transporting ATPase IIA $\mathrm{GN}=\mathrm{ATP} 9 \mathrm{~A}$

O75339 Cartilage intermediate layer protein $1 \mathrm{GN}=\mathrm{CILP}$

O75592 Probable E3 ubiquitin-protein ligase MYCBP2 $\mathrm{GN}=\mathrm{MYCBP} 2$

O76021 Ribosomal L1 domain-containing protein 1
Table III. Continued.

Protein Protein_description

O94769 Extracellular matrix protein 2 GN=ECM2

O94903 Proline synthetase co-transcribed bacterial homolog protein $\mathrm{GN}=\mathrm{PROSC}$

O95302 FK506-binding protein $9 \mathrm{GN}=$ FKBP9

O95373 Importin-7 GN=IPO7

O95425 Supervillin GN=SVIL

O95433 Activator of $90 \mathrm{kDa}$ heat shock protein ATPase homolog $1 \mathrm{GN}=\mathrm{AHSA} 1$

O95757 Heat shock $70 \mathrm{kDa}$ protein $4 \mathrm{~L} \mathrm{GN=HSPA4L}$

O95810 Serum deprivation-response protein GN=SDPR

O95816 BAG family molecular chaperone regulator 2 $\mathrm{GN}=\mathrm{BAG} 2$

O95965 Integrin $\beta$-like protein $1 \mathrm{GN}=\mathrm{ITGBL} 1$

O96005 Cleft lip and palate transmembrane protein 1 GN=CLPTM1

P01614 Ig $\kappa$ chain V-II region cum

P01781 Ig heavy chain V-III region GAL

P02724 Glycophorin-A GN=GYPA

P02750 Leucine-rich $\alpha$-2-glycoprotein GN=LRG1

P04433 Ig $\kappa$ chain V-III region VG (fragment)

P05543 Thyroxine-binding globulin GN=SERPINA7

P05546 Heparin cofactor 2 GN=SERPIND1

P07093 Glia-derived nexin GN=SERPINE2

P07358 Complement component $\mathrm{C} 8 \beta$ chain $\mathrm{GN}=\mathrm{C} 8 \mathrm{~B}$

P08174

$\mathrm{P} 08253$

$\mathrm{P} 08493$

P08708

P10253

P10451

P10600

P11234

P12004

P12107

Complement decay-accelerating factor $\mathrm{GN}=\mathrm{CD} 55$

$72 \mathrm{kDa}$ type IV collagenase GN=MMP2

Matrix Gla protein $\mathrm{GN}=\mathrm{MGP}$

40S ribosomal protein $\mathrm{S} 17 \mathrm{GN}=\mathrm{RPS} 17$

Lysosomal $\alpha$-glucosidase GN=GAA

Osteopontin GN=SPP1

Transforming growth factor $\beta-3$ GN=TGFB3

Ras-related protein Ral-B GN=RALB

P15104

P19367

P20036

Proliferating cell nuclear antigen $\mathrm{GN}=\mathrm{PCNA}$

Collagen $\alpha-1(\mathrm{XI})$ chain $\mathrm{GN}=\mathrm{COL} 11 \mathrm{~A} 1$

Glutamine synthetase GN=GLUL

Hexokinase-1 GN=HK1

HLA class II histocompatibility antigen, DP $\alpha$ chain GN=HLA-DPA 1

P20591 Interferon-induced GTP-binding protein Mx1 $\mathrm{GN}=\mathrm{MX} 1$

P20851 C4b-binding protein $\beta$ chain $\mathrm{GN}=\mathrm{C} 4 \mathrm{BPB}$

P22102 Trifunctional purine biosynthetic protein adenosine- 3 GN=GART

P23193 Transcription elongation factor A protein 1 GN=TCEA1

P23497 Nuclear autoantigen Sp-100 GN=SP100

P26373 60S ribosomal protein L13 GN=RPL13

P26599

P26639

P28300

Polypyrimidine tract-binding protein $1 \mathrm{GN}=\mathrm{PTBP} 1$

Threonyl-tRNA synthetase, cytoplasmic GN=TARS

Protein-lysine 6-oxidase GN=LOX

P31153 S-adenosylmethionine synthetase isoform type-2 GN=MAT2A

P32321 Deoxycytidylate deaminase GN=DCTD

P35542

P35625

P35858

Serum amyloid A-4 protein $\mathrm{GN}=\mathrm{SAA} 4$

Metalloproteinase inhibitor 3 GN=TIMP3

P36969 acid labile chain GN=IGFALS

Phospholzipid hydroperoxide glutathione peroxidase, mitochondrial GN=GPX4 
Table III. Continued.

\begin{tabular}{ll} 
Protein & \multicolumn{1}{c}{ Protein_description } \\
\hline P39023 & $\begin{array}{l}\text { 60S ribosomal protein L3 GN=RPL3 } \\
\text { Myeloid cell nuclear differentiation antigen } \\
\text { P41218 }\end{array}$ \\
& $\begin{array}{l}\text { GN=MNDA } \\
\text { P41240 }\end{array}$ \\
Tyrosine-protein kinase CSK GN=CSK \\
P46108 & Peptidyl-prolyl cis-trans isomerase C GN=PPIC \\
P46109 & Crk-like protein GN=CRKL \\
P48556 & 26S proteasome non-ATPase regulatory subunit 8 \\
& GN=PSMD8
\end{tabular}

P49321 Nuclear autoantigenic sperm protein GN=NASP

P49354 Protein farnesyltransferase/geranylgeranyltransferase type- 1 subunit $\alpha$ GN=FNTA

P49458 Signal recognition particle $9 \mathrm{kDa}$ protein $\mathrm{GN}=\mathrm{SRP} 9$

P49591 Seryl-tRNA synthetase, cytoplasmic GN=SARS

P50135 Histamine N-methyltransferase GN=HNMT

P50479 PDZ and LIM domain protein 4 GN=PDLIM4

P50583 Bis (5'-nucleosyl)-tetraphosphatase (asymmetrical) $\mathrm{GN}=\mathrm{NUDT} 2$

P51148 Ras-related protein Rab-5C GN=RAB5C

P51812 Ribosomal protein S6 kinase $\alpha-3$ GN=RPS6KA3

P52788 Spermine synthase GN=SMS

P55039 Developmentally-regulated GTP-binding protein 2 $\mathrm{GN}=\mathrm{DRG} 2$

P55196 Afadin GN=MLLT4

P55212 Caspase-6 GN=CASP6

P60983 Glia maturation factor $\beta$ GN=GMFB

P61221 ATP-binding cassette sub-family E member 1 $\mathrm{GN}=\mathrm{ABCE} 1$

P61225 Ras-related protein Rap-2b GN=RAP2B

P61313 60S ribosomal protein L15 GN=RPL15

P61758 Prefoldin subunit 3 GN=VBP1

P61970 Nuclear transport factor 2 GN=NUTF2

P62195 26S protease regulatory subunit $8 \mathrm{GN}=\mathrm{PSMC5}$

P62266 40S ribosomal protein S23 GN=RPS23

P62277 40S ribosomal protein S13 GN=RPS13

P62280 40S ribosomal protein S11 GN=RPS11

P62304 Small nuclear ribonucleoprotein E GN=SNRPE

P62316 Small nuclear ribonucleoprotein Sm D2 GN=SNRPD2

P62750 60S ribosomal protein L23a GN=RPL23A

P62847 40S ribosomal protein S24 GN=RPS24

P62857 40S ribosomal protein S28 GN=RPS28

P62899 60S ribosomal protein L31 GN=RPL31

P80217 Interferon-induced $35 \mathrm{kDa}$ protein GN=IFI35

P80303 Nucleobindin-2 GN=NUCB2

P82987 ADAMTS-like protein $3 \mathrm{GN=ADAMTSL3}$

P83110 Probable serine protease HTRA3 GN=HTRA3

Q00341 Vigilin GN=HDLBP

Q03518 Antigen peptide transporter $1 \mathrm{GN}=\mathrm{TAP} 1$

Q04446 1,4- $\alpha$-glucan-branching enzyme GN=GBE1

Q06124 Tyrosine-protein phosphatase non-receptor type 11 $\mathrm{GN}=\mathrm{PTPN} 11$

Q08J23 tRNA (cytosine-5-)-methyltransferase NSUN2 GN=NSUN2

Q12965 Myosin-Ie GN=MYO1E

Q13123 Protein Red GN=IK

Q13315 Serine-protein kinase ATM GN=ATM

Q13838 Spliceosome RNA helicase BAT1 GN=BAT1

Q14011 Cold-inducible RNA-binding protein $\mathrm{GN}=\mathrm{CIRBP}$
Table III. Continued.

Protein Protein_description

Q14558 Phosphoribosyl pyrophosphate synthetase-associated protein $1 \mathrm{GN}=$ PRPSAP1

Q14699 Raftlin GN=RFTN1

Q15008 26S proteasome non-ATPase regulatory subunit 6 GN=PSMD6

Q15121 Astrocytic phosphoprotein PEA-15 GN=PEA15

Q15181 Inorganic pyrophosphatase GN=PPA1

Q15465 Sonic hedgehog protein $\mathrm{GN}=\mathrm{SHH}$

Q15907 Ras-related protein Rab-11B GN=RAB11B

Q3LXA3 Dihydroxyacetone kinase GN=DAK

Q3ZCW2 Galectin-related protein $\mathrm{GN}=\mathrm{GRP}$

Q5KU26 Collectin-12 GN=COLEC12

Q5TC82 Roquin GN=RC3H1

Q66K74 Microtubule-associated protein 1S GN=MAP1S

Q6ZVZ8 Ankyrin repeat and SOCS box-containing protein 18 $\mathrm{GN}=\mathrm{ASB} 18$

Q7Z304 MAM domain-containing protein $2 \mathrm{GN}=\mathrm{MAMDC} 2$

Q7Z333 Probable helicase senataxin GN=SETX

Q86UE8 Serine/threonine-protein kinase tousled-like 2 $\mathrm{GN}=\mathrm{TLK} 2$

Q86W92 Liprin- $\beta$-1 GN=PPFIBP1

Q86X55 Histone-arginine methyltransferase CARM1 $\mathrm{GN}=\mathrm{CARM} 1$

Q8IWE2 Protein NOXP20 GN=FAM114A1

Q8IWU6 Extracellular sulfatase Sulf-1 GN=SULF1

Q8IXB1 DnaJ homolog subfamily C member 10 $\mathrm{GN}=\mathrm{DNAJC} 10$

Q8IXM2 Uncharacterized potential DNA-binding protein C17orf49 GN=C17orf49

Q8N129 Protein canopy homolog 4 GN=CNPY4

Q8N573 Oxidation resistance protein $1 \mathrm{GN}=\mathrm{OXR} 1$

Q8N6Q3 CD177 antigen $\mathrm{GN}=\mathrm{CD} 177$

Q8NB37 Parkinson disease 7 domain-containing protein 1 $\mathrm{GN}=\mathrm{PDDC} 1$

Q8TDX7 Serine/threonine-protein kinase Nek7 GN=NEK7

Q8WWI1 LIM domain only protein $7 \mathrm{GN}=\mathrm{LMO} 7$

Q92673 Sortilin-related receptor GN=SORL1

Q92696 Geranylgeranyl transferase type-2 subunit $\alpha$ GN=RABGGTA

Q92882 Osteoclast-stimulating factor $1 \mathrm{GN}=\mathrm{OSTF} 1$

Q93009 Ubiquitin carboxyl-terminal hydrolase 7 GN=USP7

Q96AT9 Ribulose-phosphate 3-epimerase GN=RPE

Q96C23 Aldose 1-epimerase GN=GALM

Q96CG8 Collagen triple helix repeat-containing protein 1 $\mathrm{GN}=\mathrm{CTHRC} 1$

Q96CV9 Optineurin GN=OPTN

Q96FW1 Ubiquitin thioesterase OTUB1 GN=OTUB1

Q96GS4 Uncharacterized protein C17orf59 GN=C17orf59

Q96HF1 Secreted frizzled-related protein $2 \mathrm{GN}=\mathrm{SFRP} 2$

Q96HN2 Putative adenosylhomocysteinase 3 GN=AHCYL2

Q96JB1 Dynein heavy chain 8, axonemal GN=DNAH8

Q96JQ2 Calmin GN=CLMN

Q96MM6 Heat shock $70 \mathrm{kDa}$ protein 12B GN=HSPA12B

Q96N66 Membrane-bound O-acyltransferase domain-containing protein $7 \mathrm{GN}=$ MBOAT7

Q96PX9 Pleckstrin homology domain-containing family $\mathrm{G}$ member 4B GN=PLEKHG4B

Q96RF0 Sorting nexin-18 GN=SNX18

Q96RL7 Vacuolar protein sorting-associated protein 13A $\mathrm{GN}=\mathrm{VPS} 13 \mathrm{~A}$ 
Table III. Continued.

\begin{tabular}{ll} 
Protein & \multicolumn{1}{c}{ Protein_description } \\
\hline Q99426 & Tubulin folding cofactor B GN=TBCB \\
Q99538 & Legumain GN=LGMN \\
Q99622 & Protein C10 GN=C12orf57 \\
Q99627 & COP9 signalosome complex subunit 8 GN=COPS8 \\
Q9BRG1 & Vacuolar protein-sorting-associated protein 25 \\
& GN=VPS25 \\
Q9BUT1 & 3-hydroxybutyrate dehydrogenase type 2 GN=BDH2 \\
Q9BVJ7 & Dual specificity protein phosphatase 23 \\
& GN=DUSP23 \\
Q9BXJ0 & Complement C1q tumor necrosis factor-related \\
& protein 5 GN=C1QTNF5 \\
Q9BXP5 & Arsenite-resistance protein 2 GN=ARS2 \\
Q9BXS5 & AP-1 complex subunit mu-1 GN=AP1M1 \\
Q9BY32 & Inosine triphosphate pyrophosphatase GN=ITPA \\
Q9H0W9 & Ester hydrolase C11orf54 GN=C11orf54 \\
Q9H2D6 & TRIO and F-actin-binding protein GN=TRIOBP \\
Q9H488 & GDP-fucose protein O-fucosyltransferase 1 \\
& GN=POFUT1 \\
Q9H6V9 & UPF0554 protein C2orf43 GN=C2orf43 \\
Q9HAB8 & Phosphopantothenate-cysteine ligase GN=PPCS \\
Q9HB40 & Retinoid-inducible serine carboxypeptidase \\
& GN=SCPEP1
\end{tabular}

Q9HCJ1 Progressive ankylosis protein homolog $\mathrm{GN}=\mathrm{ANKH}$

Q9NQR4 Nitrilase homolog 2 GN=NIT2

Q9NRN5 Olfactomedin-like protein $3 \mathrm{GN}=$ OLFML3

Q9NS15 Latent-transforming growth factor $\beta$-binding protein 3 $\mathrm{GN}=\mathrm{LTBP} 3$

Q9NZL9 Methionine adenosyltransferase 2 subunit $\beta$ $\mathrm{GN}=\mathrm{MAT} 2 \mathrm{~B}$

Q9P258 Protein RCC2 GN=RCC2

Q9UBB6 Neurochondrin GN=NCDN

Q9UBR2 Cathepsin Z GN=CTSZ

Q9UBW8 COP9 signalosome complex subunit $7 \alpha$ GN=COPS7A

Q9UDY2 Tight junction protein $\mathrm{ZO}-2 \mathrm{GN}=\mathrm{TJP} 2$

Q9UEY8 $\gamma$-adducin GN=ADD3

Q9UHL4 Dipeptidyl-peptidase 2 GN=DPP7

Q9UHY7 Enolase-phosphatase E1 GN=ENOPH1

Q9UJC5 SH3 domain-binding glutamic acid-rich-like protein 2 $\mathrm{GN}=\mathrm{SH} 3 \mathrm{BGRL} 2$

Q9UKU9 Angiopoietin-related protein $2 \mathrm{GN}=\mathrm{ANGPTL} 2$

Q9UM19 Hippocalcin-like protein $4 \mathrm{GN}=\mathrm{HPCAL} 4$

Q9UM47 Neurogenic locus notch homolog protein 3 $\mathrm{GN}=\mathrm{NOTCH} 3$

Q9UM54 Myosin-VI GN=MYO6

Q9UMS0 NFU1 iron-sulfur cluster scaffold homolog, mitochondrial GN=NFU1

Q9UNF0 Protein kinase $\mathrm{C}$ and casein kinase substrate in neurons protein $2 \mathrm{GN}=\mathrm{PACSIN} 2$

Q9UNH6 Sorting nexin-7 GN=SNX7

Q9UPN7 Serine/threonine-protein phosphatase 6 regulatory subunit $1 \mathrm{GN}=\mathrm{SAPS} 1$

Q9Y266 Nuclear migration protein nudC GN=NUDC

Q9Y287 Integral membrane protein 2B GN=ITM2B

Q9Y3C6 Peptidyl-prolyl cis-trans isomerase-like $1 \mathrm{GN}=\mathrm{PPIL} 1$

Q9Y4E8 Ubiquitin carboxyl-terminal hydrolase 15 GN=USP15

Q9Y5K8 V-type proton ATPase subunit D GN=ATP6V1D

Q9Y5U9 Immediate early response 3-interacting protein 1 GN=IER3IP1

Q9Y5X1 Sorting nexin-9 GN=SNX9
Table III. Continued.

\begin{tabular}{ll}
\hline Protein & \multicolumn{1}{c}{ Protein_description } \\
\hline Q9Y5X3 & Sorting nexin-5 GN=SNX5 \\
Q9Y6K5 & 2'-5'-Oligoadenylate synthetase 3 GN=OAS3 \\
Q9Y6R7 & IgGFc-binding protein GN=FCGBP \\
O43765 & $\begin{array}{l}\text { Small glutamine-rich tetratricopeptide } \\
\text { repeat-containing protein } \alpha \text { GN=SGTA }\end{array}$ \\
O60749 & $\begin{array}{l}\text { Sorting nexin-2 GN=SNX2 } \\
\text { Q12765 }\end{array}$ \\
Secernin-1 GN=SCRN1 \\
Q8N0U8 & $\begin{array}{l}\text { Vitamin K epoxide reductase complex subunit 1-like } \\
\text { protein 1 GN=VKORC1L1 }\end{array}$ \\
Q9NYL4 & FK506-binding protein 11 GN=FKBP11 \\
\hline
\end{tabular}

Table IV. Upregulated proteins (115).

Protein Protein_description

O00148 ATP-dependent RNA helicase DDX39 GN=DDX39

O00330 Pyruvate dehydrogenase protein X component, mitochondrial GN=PDHX

O00629 Importin subunit $\alpha-4$ GN=KPNA4

O00748 Carboxylesterase 2 GN=CES2

O14958 Calsequestrin-2 GN=CASQ2

O43676 NADH dehydrogenase (ubiquinone) $1 \beta$ subcomplex subunit 3 GN=NDUFB3

O60784 Target of Myb protein $1 \mathrm{GN}=\mathrm{TOM} 1$

O75112 LIM domain-binding protein $3 \mathrm{GN}=\mathrm{LDB} 3$

O75128 Protein cordon-bleu $\mathrm{GN}=\mathrm{COBL}$

O75298 Reticulon-2 GN=RTN2

O75306 NADH dehydrogenase (ubiquinone) iron-sulfur protein 2, mitochondrial GN=NDUFS2

O94826 Mitochondrial import receptor subunit TOM70 $\mathrm{GN}=\mathrm{TOMM} 70 \mathrm{~A}$

O94906 Pre-mRNA-processing factor $6 \mathrm{GN}=\mathrm{PRPF} 6$

O94925 Glutaminase kidney isoform, mitochondrial GN=GLS

095248 Myotubularin-related protein $5 \mathrm{GN}=\mathrm{SBF} 1$

O95299 NADH dehydrogenase (ubiquinone) $1 \alpha$ subcomplex subunit 10, mitochondrial GN=NDUFA10

P02585 Troponin C, skeletal muscle GN=TNNC2

P05166 Propionyl-CoA carboxylase $\beta$ chain, mitochondrial GN=PCCB

P06732 Creatine kinase M-type GN=CKM

P07451 Carbonic anhydrase $3 \mathrm{GN}=\mathrm{CA} 3$

P08590 Myosin light chain 3 GN=MYL3

P10916 Myosin regulatory light chain 2, ventricular/cardiac muscle isoform $\mathrm{GN}=\mathrm{MYL} 2$

P11217 Glycogen phosphorylase, muscle form GN=PYGM

P11233 Ras-related protein Ral-A GN=RALA

P13805 Troponin T, slow skeletal muscle GN=TNNT1

P13807 Glycogen (starch) synthase, muscle GN=GYS1

P14649 Myosin light chain 6B GN=MYL6B

P19237 Troponin I, slow skeletal muscle GN=TNNI1

P23327 Sarcoplasmic reticulum histidine-rich calcium-binding protein $\mathrm{GN}=\mathrm{HRC}$

P28289 Tropomodulin-1 GN=TMOD1

P29218 Inositol monophosphatase GN=IMPA1

P30038 $\delta$-1-pyrroline-5-carboxylate dehydrogenase, mitochondrial GN=ALDH4A1

P31513 Dimethylaniline monooxygenase (N-oxide-forming) 3 $\mathrm{GN}=\mathrm{FMO} 3$ 
Table IV. Continued.

Protein Protein_description

\begin{tabular}{|c|c|}
\hline P35080 & Profilin $-2 \mathrm{GN}=\mathrm{PFN} 2$ \\
\hline P35609 & $\alpha$-actinin-2 GN=ACTN2 \\
\hline P42704 & $\begin{array}{l}\text { Leucine-rich PPR motif-containing protein, } \\
\text { mitochondrial GN=LRPPRC }\end{array}$ \\
\hline P45378 & Troponin T, fast skeletal muscle GN=TNNT3 \\
\hline P48788 & Troponin I, fast skeletal muscle GN=TNNI2 \\
\hline P50461 & Cysteine and glycine-rich protein $3 \mathrm{GN}=\mathrm{CSRP} 3$ \\
\hline P51553 & $\begin{array}{l}\text { Isocitrate dehydrogenase (NAD) subunit } \gamma \text {, } \\
\text { mitochondrial GN=IDH3G }\end{array}$ \\
\hline P52179 & Myomesin-1 GN=MYOM1 \\
\hline P54296 & Myomesin-2 GN=MYOM2 \\
\hline P63316 & $\begin{array}{l}\text { Troponin C, slow skeletal and } \\
\text { cardiac muscles GN=TNNC1 }\end{array}$ \\
\hline Q00872 & Myosin-binding protein $\mathrm{C}$, slow-type $\mathrm{GN}=\mathrm{MYBPC} 1$ \\
\hline Q02045 & Myosin light chain 5 GN=MYL5 \\
\hline Q09013 & Myotonin-protein kinase GN=DMPK \\
\hline Q10589 & Bone marrow stromal antigen $2 \mathrm{GN}=\mathrm{BST} 2$ \\
\hline Q13061 & Triadin GN=TRDN \\
\hline Q14118 & Dystroglycan GN=DAG1 \\
\hline Q14324 & Myosin-binding protein C, fast-type GN=MYBPC2 \\
\hline Q15111 & Inactive phospholipase $\mathrm{C}$-like protein $1 \mathrm{GN}=\mathrm{PLCL} 1$ \\
\hline Q16630 & $\begin{array}{l}\text { Cleavage and polyadenylation specificity factor } \\
\text { subunit } 6 \mathrm{GN}=\mathrm{CPSF} 6\end{array}$ \\
\hline Q16775 & Hydroxyacylglutathione hydrolase $\mathrm{GN}=\mathrm{HAGH}$ \\
\hline
\end{tabular}

Q16775 Hydroxyacylglutathione hydrolase $\mathrm{GN}=\mathrm{HAGH}$

Q5BKX8 PTRF/SDPR family protein

Q5T1J5 Coiled-coil-helix-coiled-coil-helix

domain-containing protein 9 ,

mitochondrial $\mathrm{GN}=\mathrm{CHCHD} 9$

Q5VTT5 Myomesin-3 GN=MYOM3

Q5VXT5 Synaptophysin-like protein $2 \mathrm{GN}=\mathrm{S}$ YPL2

Q5W0V3 UPF0518 protein FAM160B1 GN=FAM160B1

Q6ZMU5 Tripartite motif-containing protein 72 GN=TRIM72

Q702N8 Xin actin-binding repeat-containing protein 1

$\mathrm{GN}=\mathrm{XIRP} 1$

Q86TD4 Sarcalumenin GN=SRL

Q86UW8 Hyaluronan and proteoglycan link protein 4 $\mathrm{GN}=\mathrm{HAPLN} 4$

Q86VU5 Catechol-O-methyltransferase domain-containing protein $1 \mathrm{GN}=\mathrm{COMTD} 1$

Q8IWX7 Protein unc-45 homolog B GN=UNC45B

Q8IZL8 Proline-, glutamic acid- and leucine-rich protein 1 $\mathrm{GN}=\mathrm{PELP} 1$

Q8N1G4 Leucine-rich repeat-containing protein 47 $\mathrm{GN}=\mathrm{LRRC} 47$

Q8NE86 Coiled-coil domain-containing protein 109A $\mathrm{GN}=\mathrm{CCDC} 109 \mathrm{~A}$

Q8NF37 1-acylglycerophosphocholine O-acyltransferase 1 GN=LPCAT1

Q8NFW1 Collagen $\alpha-1$ (XXII) chain GN=COL22A1

Q8NI60 Chaperone activity of bc1 complex-like, mitochondrial $\mathrm{GN}=\mathrm{CABC} 1$

Q8WW22 DnaJ homolog subfamily A member 4 $\mathrm{GN}=\mathrm{DNAJA} 4$

Q92629 $\delta$-sarcoglycan GN=SGCD

Q96A32 Myosin regulatory light chain 2, skeletal muscle isoform GN=MYLPF

Q96EY8 Cob(I)yrinic acid a,c-diamide adenosyltransferase, mitochondrial GN=MMAB

Q9BQS8 FYVE and coiled-coil domain-containing protein 1 $\mathrm{GN}=\mathrm{FYCO} 1$
Table IV. Continued.

\begin{tabular}{|c|c|}
\hline Protein & Protein_description \\
\hline Q9BWD1 & $\begin{array}{l}\text { Acetyl-CoA acetyltransferase, } \\
\text { cytosolic } \mathrm{GN}=\mathrm{ACAT} 2\end{array}$ \\
\hline Q9GZV1 & $\begin{array}{l}\text { Ankyrin repeat domain-containing protein } 2 \\
\text { GN=ANKRD2 }\end{array}$ \\
\hline Q9HC07 & Transmembrane protein 165 GN=TMEM165 \\
\hline Q9NP98 & Myozenin-1 GN=MYOZ1 \\
\hline Q9NPC6 & Myozenin-2 GN=MYOZ2 \\
\hline Q9NTI5 & $\begin{array}{l}\text { Sister chromatid cohesion protein PDS5 homolog B } \\
\text { GN=PDS5B }\end{array}$ \\
\hline Q9NZQ9 & Tropomodulin-4 GN=TMOD4 \\
\hline Q9UBF9 & Myotilin GN=MYOT \\
\hline Q9UKS6 & $\begin{array}{l}\text { Protein kinase } \mathrm{C} \text { and casein kinase substrate } \\
\text { in neurons protein } 3 \mathrm{GN}=\mathrm{PACSIN} 3\end{array}$ \\
\hline Q9Y235 & $\begin{array}{l}\text { Probable C-)U-editing enzyme APOBEC-2 } \\
\text { GN=APOBEC } 2\end{array}$ \\
\hline Q9Y2J8 & Protein-arginine deiminase type- $2 \mathrm{GN}=\mathrm{PADI} 2$ \\
\hline Q9Y639 & Neuroplastin GN=NPTN \\
\hline P12883 & Myosin-7 GN=MYH7 \\
\hline P31415 & Calsequestrin-1 GN=CASQ1 \\
\hline P20929 & Nebulin GN=NEB \\
\hline Q8WZ42 & Titin GN=TTN \\
\hline P05976 & $\begin{array}{l}\text { Myosin light chain 1, skeletal muscle isoform } \\
\text { GN=MYL1 }\end{array}$ \\
\hline P02144 & Myoglobin GN=MB \\
\hline P11532 & Dystrophin GN=DMD \\
\hline Q14315 & Filamin-C GN=FLNC \\
\hline Q9UHQ9 & NADH-cytochrome b5 reductase $1 \mathrm{GN}=\mathrm{CYB} 5 \mathrm{R} 1$ \\
\hline Q9NZ01 & Synaptic glycoprotein SC2 GN=GPSN2 \\
\hline Q13740 & $\mathrm{CD} 166$ antigen $\mathrm{GN}=\mathrm{ALCAM}$ \\
\hline O95817 & $\begin{array}{l}\text { BAG family molecular chaperone regulator } 3 \\
\text { GN=BAG3 }\end{array}$ \\
\hline P25786 & Proteasome subunit $\alpha$ type- 1 GN=PSMA1 \\
\hline Q01130 & Splicing factor, arginine/serine-rich 2 GN=SFRS2 \\
\hline P12235 & $\mathrm{ADP} / \mathrm{ATP}$ translocase $1 \mathrm{GN}=\mathrm{SLC} 25 \mathrm{~A} 4$ \\
\hline P13929 & $\beta$-enolase $\mathrm{GN}=\mathrm{ENO} 3$ \\
\hline O75923 & Dysferlin GN=DYSF \\
\hline P53634 & Dipeptidyl-peptidase $1 \mathrm{GN}=\mathrm{CTSC}$ \\
\hline $\mathrm{P} 23258$ & Tubulin $\gamma-1$ chain GN=TUBG1 \\
\hline O75746 & $\begin{array}{l}\text { Calcium-binding mitochondrial carrier protein } \\
\text { Aralar1 GN=SLC25A12 }\end{array}$ \\
\hline O94919 & $\begin{array}{l}\text { Endonuclease domain-containing } 1 \text { protein } \\
\text { GN=ENDOD1 }\end{array}$ \\
\hline P24043 & Laminin subunit $\alpha-2 \mathrm{GN}=\mathrm{LAMA} 2$ \\
\hline P11216 & Glycogen phosphorylase, brain form $\mathrm{GN}=\mathrm{PYGB}$ \\
\hline P12829 & Myosin light chain 4 GN=MYL4 \\
\hline P55042 & GTP-binding protein RAD GN=RRAD \\
\hline P62491 & Ras-related protein Rab-11A GN=RAB $11 \mathrm{~A}$ \\
\hline Q14BN4 & $\begin{array}{l}\text { Sarcolemmal membrane-associated protein } \\
\text { GN=SLMAP }\end{array}$ \\
\hline Q96JG9 & Zinc finger protein $469 \mathrm{GN}=\mathrm{ZNF} 469$ \\
\hline
\end{tabular}

nucleotide metabolism, amino acid metabolism, carbohydrate metabolism, genetic information processing and translation, and biosynthesis of other secondary metabolites.

To further determine the cellular function change between CSO and CRO, the statistically significant 359 proteins identified were classified according to gene ontology 


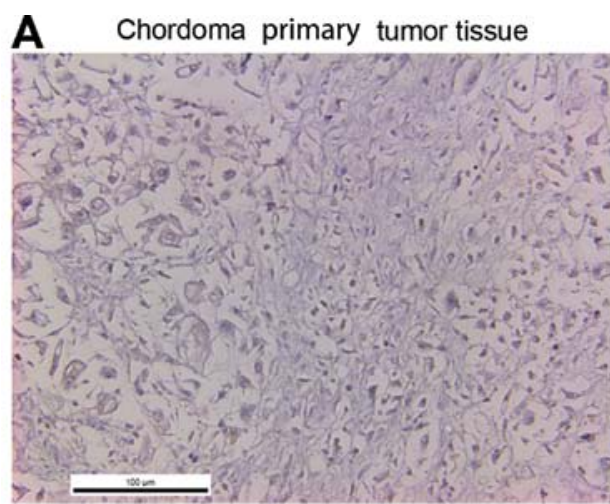

B Chordoma recurrent tumor tissue

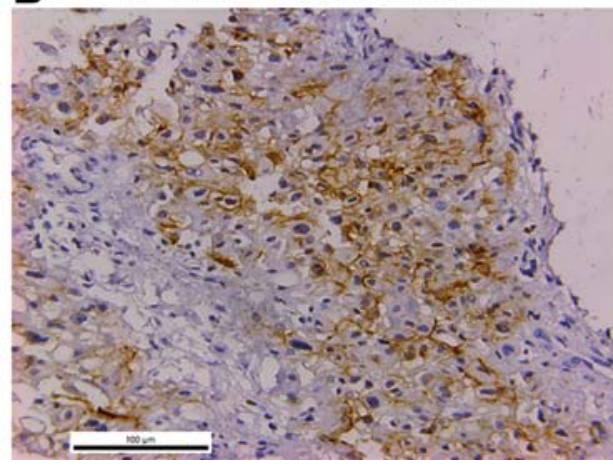

Chordoma primary tumor tissue

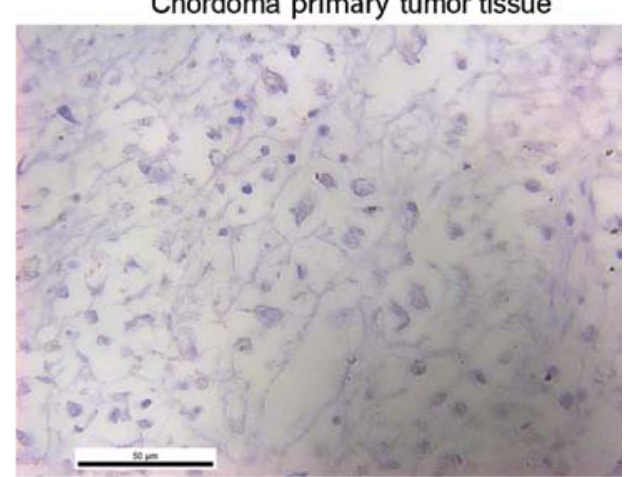

Chordoma recurrent tumor tissue

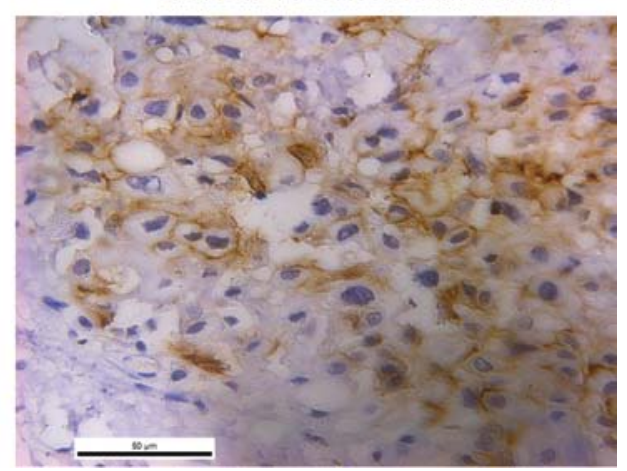

Figure 5. Immunohistochemistry of ALCAM in CSO and CSR. CSO, chordoma primary tumor; CSR, recurrent tumor.

terms. The proteins were found to be involved in either a biological process, a cellular component and/or a molecular function (Fig. 4), indicating that there were diverse cellular components and catalytic activity change in recurrent chordomas compared to the original chordoma. Furthermore, when the identified proteins in the recurrent chordoma were mapped to the corresponding metabolic pathways, many key cellular pathways including amino acid, carbohydrate metabolism, energy, and nucleotide metabolism were found to be downregulated (Fig. 4).

In order to confirm our results from the proteome, we examined tumor-related protein expression from the list of upregulated proteins through IHC in the chordoma patient primary and CSR tissues. ALCAM (or CD166) is a 100-105 kDa type I transmembrane glycoprotein that is a member of the immunoglobulin superfamily of proteins (21). ALCAM has been reported as a cancer stem cell marker for non-small cell lung cancer (NSCLC) (15). Physiologically, it plays a role in the development of different tissues during embryogenesis. It is also expressed in various malignant lesions such as melanoma and esophageal, gynecologic, prostate, and pancreatic cancers, and its expression is associated with diverse outcomes in different tumors (22-32). But the expression of ALCAM in chordomas has never been reported and the association between ALCAM and chordoma prognosis is not fully elucidated. In our study, we firstly detected ALCAM expression by using IHC in chordoma patient primary and CSR tissues. Fig. 5A clearly demonstrates that the primary chordoma tumor was negative for staining; however, the CSR had strong expression of ALCAM which suggests that ALCAM is a positive biomarker for recurrent chordomas and may play important roles for chordoma recurrence (Fig. 5B).
In conclusion, we analyzed the proteomic profile of a chordoma patient CSO and CSR and identified 359 proteins and 21 pathways with significant changes between CSO and CSR. Many of these molecular changes are reported in chordomas for the first time. Further investigation of the potential roles of these proteins in chordoma aggression is of interest. We also firstly found that the recurrent chordoma tumor showed enhanced carbohydrate metabolism, and the cancer stem cell marker ALCAM (CD166) expression level was increased markedly in CSR. The present study can serve as the basis for further research of recurrent chordomas.

\section{Acknowledgements}

The present study was supported by the National Nature Science Foundation for Distinguished Young Scholars of China (no. 81102036/H1624), the National Basic Research Program (no. 81272943), and the Nature Science Foundation of Shanghai (no. 12JC1411300).

\section{References}

1. Stacchiotti S, Casali PG, Lo Vullo S, et al: Chordoma of the mobile spine and sacrum: a retrospective analysis of a series of patients surgically treated at two referral centers. Ann Surg Oncol 17: 211-219, 2010

2. DeLaney TF, Liebsch NJ, Pedlow FX, et al: Phase II study of high-dose photon/proton radiotherapy in the management of spine sarcomas. Int J Radiat Oncol Biol Phys 74: 732-739, 2009.

3. Zhou H, Chen CB, Lan J, et al: Differential proteomic profiling of chordomas and analysis of prognostic factors. J Surg Oncol 102: 720-727, 2010.

4. Wisniewski JR, Zougman A, Nagaraj N and Mann M: Universal sample preparation method for proteome analysis. Nat Methods 6: 359-362, 2009. 
5. Vogel C and Marcotte EM: Calculating absolute and relative protein abundance from mass spectrometry-based protein expression data Nat Protoc 3: 1444-1451, 2008.

6. Lu P, Vogel C, Wang R, Yao X and Marcotte EM: Absolute protein expression profiling estimates the relative contributions of transcriptional and translational regulation. Nat Biotechnol 25: 117-124, 2007.

7. Benjamini Y and Hochberg Y: Controlling the false discovery rate - a practical and powerful approach to multiple testing. J R Stat Soc B 57: 289-300, 1995.

8. Conesa A, Gotz S, Garcia-Gomez JM, Terol J, Talon M and Robles M: Blast2GO: a universal tool for annotation, visualization and analysis in functional genomics research. Bioinformatics 21 : 3674-3676, 2005

9. Yamada T, Letunic I, Okuda S, Kanehisa M and Bork P: IPath2.0: interactive pathway explorer. Nucleic Acids Res 39: W412-W415, 2011.

10. Shimizu-Hirota R, Sasamura H, Kuroda M, Kobayashi E and Saruta T: Functional characterization of podocan, a member of a new class in the small leucine-rich repeat protein family. FEBS Lett 563: 69-74, 2004.

11. Hoover KB, Liao SY and Bryant PJ: Loss of the tight junction MAGUK ZO-1 in breast cancer: relationship to glandular differentiation and loss of heterozygosity. Am J Pathol 153: 1767-1773, 1998.

12. Liu W, Liu B, Xin L, Zhang Y, Chen X, Zhu Z and Lin Y: Downregulated expression of complement factor I: a potential suppressive protein for gastric cancer identified by serum proteome analysis. Clin Chim Acta 377: 119-126, 2007.

13. Ohnuma SI: Cancer diagnosis and treatment. Google Patents, 2011.

14. Ostrow KL, Park HL, Hoque MO, et al: Pharmacologic unmasking of epigenetically silenced genes in breast cancer. Clin Cancer Res 15: 1184-1191, 2009.

15. Tachezy M, Zander $\mathrm{H}$ and Wolters-Eisfeld G: Activated leukocyte cell adhesion molecule (CD166): an 'inert' cancer stem cell marker for non-small cell lung cancer? Stem Cells 32 1429-1436, 2014

16. Ibrahim SA, Reed KR, Clarke AR, Pritchard DM and Jenkins JR Sa1992 SFRS2 and CDC5L interaction: an insight into downstream events following APC deletion during colorectal carcinogenesis. Gastroenterology 144: S353-S354, 2013.

17. Palmieri D, Bouadis A, Ronchetti R, Merino MJ and Steeg PS Rab1la differentially modulates epidermal growth factor-induced proliferation and motility in immortal breast cells. Breast Cancer Res Treat 100: 127-137, 2006.

18. Klement RJ and Kammerer U: Is there a role for carbohydrate restriction in the treatment and prevention of cancer? Nutr Metab 8: 75,2011 .
19. Walenta S, Wetterling M, Lehrke M, Schwickert G, Sundfør K, Rofstad EK and Mueller-Klieser W: High lactate levels predict likelihood of metastases, tumor recurrence, and restricted patient survival in human cervical cancers. Cancer Res 60: 916-921, 2000.

20. Seyfried TN and Shelton LN: Cancer as a metabolic disease. Nutr Metab 7: 7, 2010.

21. Skonier JE, Bowen MA, Emswiler J, Aruffo A and Bajorath J: Recognition of diverse proteins by members of the immunoglobulin superfamily: delineation of the receptor binding site in the human CD6 ligand ALCAM. Biochemistry 35: 12287-12291, 1996.

22. Weidle HU, Eggle D, Klostermann S and Swart GW: ALCAM/ CD166: cancer-related issues. Cancer Genom Proteom 7: 231-243, 2010.

23. Van Kilsdonk JW, Wilting RH, Bergers M, van Muijen GN, Schalkwijk J, van Kempen LL, and Swart GW: Attenuation of melanoma invasion by a secreted variant of activated leukocyte cell adhesion molecule. Cancer Res 68: 3671-3679, 2008.

24. Ofori-Acquah SF and King JA: Activated leukocyte cell adhesion molecule: a new paradox in cancer. Transl Res 151: 122-128,2008.

25. Ihnen M, Müller V, Wirtz RM, et al: Predictive impact of activated leukocyte cell adhesion molecule (ALCAM/CD166) in breast cancer. Breast Cancer Res Treat 112: 419-427, 2008.

26. Mezzanzanica D, Fabbi M, Bagnoli M, et al: Subcellular localization of activated leukocyte cell adhesion molecule is a molecular predictor of survival in ovarian carcinoma patients. Clin Cancer Res 14: 1726-1733, 2008.

27. Tachezy M,Zander H, Marx AH, Stahl PR, Gebauer F, Izbicki JR and Bockhornet M: ALCAM (CD166) expression and serum levels in pancreatic cancer. PLoS One 7: e39018, 2012.

28. Tachezy M, Effenberger K, Zander H, et al: ALCAM (CD166) expression and serum levels are markers for poor survival of esophageal cancer patients. Int J Cancer 131: 396-405, 2012.

29. Tachezy M, Zander H, Gebauer F, Marx A, Kaifi JT, Izbicki JR and Bockhorn M: Activated leukocyte cell adhesion molecule (CD166) - its prognostic power for colorectal cancer patients. J Surg Res 177: e15-e20, 2012.

30. Tachezy M, Zander H, Marx AH, et al: ALCAM (CD166) expression as novel prognostic biomarker for pancreatic neuroendocrine tumor patients. J Surg Res 170: 226-232, 2011.

31. Ishiguro F, Murakami H, Mizuno T, et al: Membranous expression of activated leukocyte cell adhesion molecule contributes to poor prognosis and malignant phenotypes of non-small-cell lung cancer. J Surg Res 179: 24-32, 2013.

32. Simon R, Mirlacher M and Sauter G: Immunohistochemical analysis of tissue microarrays. Methods Mol Biol 664: 113-126, 2010. 